\title{
PREDIÇÃO DO CONTEÚDO DE AMINOÁCIDOS ESSENCIAIS DO GRÃO DE MILHO
}

\author{
Prediction of essencial amino acid content of corn grain
}

\author{
Vanessa Piovesan ${ }^{1}$, Vladimir de Oliveira ${ }^{2}$, Jocélio dos Santos Araújo ${ }^{3}$
}

\begin{abstract}
RESUMO
O experimento foi conduzido para determinar a relação entre aminoácidos e frações nitrogenadas do grão de milho (Zea mays L.) e verificar a possibilidade de utilizar tais relações para estimar o conteúdo de alguns aminoácidos. Selecionaram-se 45 amostras de diferentes híbridos de milho cultivados na região oeste do Paraná que foram agrupadas em três categorias, de acordo com o teor de proteína bruta (baixo, médio e alto). Posteriormente, retirou-se uma sub amostra aleatória dentro de cada uma das categorias anteriores, que resultou em uma sub amostra de 15 milhos, os quais foram submetidos à análise de aminoácidos e teor de nitrogênio não-protéico (NNP). O conteúdo de proteína bruta corrigida ( $\mathrm{PBc}$ ) foi obtida descontando-se a concentração de NNP dos valores de proteína bruta. A estrutura de relação entre as variáveis foi estudada por correlação de Pearson e os modelos de regressão linear ajustados pelo método dos quadrados mínimos. Os coeficientes angulares das retas dos primeiros aminoácidos limitantes para aves e suínos (lisina, metionina e treonina) foram positivos e significativos (LIS $=0,1080+0,0140 \mathrm{~PB}, \mathrm{R}^{2}=0,39$; $\mathrm{MET}=0,1015+0,0084 \mathrm{~PB}, \mathrm{R}^{2}=0,43$, TRE $=0,1268+0,0184 * \mathrm{~PB}, \mathrm{R}^{2}=0,51$ ). Contudo, os coeficientes de determinação das equações foram abaixo de 0,51 , indicando que a PB explica apenas uma parte da variação no conteúdo de aminoácidos do grão de milho. A predição dos aminoácidos essenciais não melhorou com a utilização da PBc como variável independente. Conclui-se que não é possível estimar, com a precisão adequada, o conteúdo de aminoácidos essenciais do grão de milho, utilizando-se como variáveis independentes a proteína bruta ou a proteína bruta corrigida.
\end{abstract}

Termos para indexação: Equações de regressão, formulação de rações, Zea mays, nutrição animal.

\section{ABSTRACT}

An experiment was conducted to evaluate the relationship between amino acids and nitrogen fractions of corn grain (Zea mays L.) and verify whether it is possible to use such relations to estimate amino acid contents. Forty five samples of corn hybrids cultivated in West of the State of Paraná were obtained and grouped in three categories according to the level of crude protein (low, medium and high). Afterwards, a random sub-sample was taken from each of the previous categories, resulting in a sub-sample of 15 corn hybrids that were taken out and submitted to amino acid and non-protein nitrogen (NNP) analysis. The content of corrected crude protein $(\mathrm{CCP})$ was obtained by reducing the NNP concentration of $\mathrm{CP}$ values. The relation between variables was studied by Pearson Correlation and lineal regression models adjusted by the minimum square method. The angular coefficients of the first limiting amino acids for birds and swine (lysine, methionine and threonine) were positive and significant (LYS $=0.1080+0.0140 \mathrm{CP}$, $\mathrm{R}^{2}=0.39$; MET $=0.1015+0.0084 \mathrm{CP}, \mathrm{R}^{2}=0.43$, THR $=0.1268+0.0184 \mathrm{CP}, \mathrm{R}^{2}=0.51$ ). However, the determination coefficients of equations were lower than 0.51 , showing that $\mathrm{CP}$ explains only part of the variation in the amino acid content of corn grain. The prediction of limiting amino acids did not improve when CCP was used as an independent variable. Based on the regression analysis, it is not possible to estimate precisely the content of essential amino acids of corn grain using as independent variables crude protein or corrected crude protein.

Index terms: Animal nutrition, diet formulation, Zea mays, regression equations.

(Recebido em 26 de novembro de 2007 e aprovado em 17 de agosto de 2009)

\section{INTRODUÇÃO}

Conhecer o conteúdo de aminoácidos dos ingredientes utilizados nas rações de aves e suínos é importante, tanto para o aproveitamento mais eficiente dos alimentos, como para a nutrição mais adequada desses animais.

A determinação dos aminoácidos normalmente é realizada por meio de cromatografia líquida de alta eficiência
(HPLC), que é de custo elevado, pois exige equipamentos e reagentes onerosos (Brandt et al., 2000). Além disso, poucos laboratórios realizam rotineiramente essas análises em alimentos para animais. Uma das soluções para o problema consiste em estimar o conteúdo de aminoácidos dos ingredientes, utilizando-se equações de regressão. Essa é uma alternativa que pode diminuir o custo e aumentar a rapidez da análise de aminoácidos (Brandt et al., 2000; Cervantes et al., 2002).

\footnotetext{
1Universidade Estadual do Oeste do Paraná - Marechal Cândido Rondon, Paraná

${ }^{2}$ Universidade Federal de Santa Catarina/UFSC - Rodovia Admar Gonzaga - 1346 - Cx.P.476 - 88040-900 - Florianópolis, SC v_olliveira@yahoo.com.br

3̄nniversidade Federal do Maranhão/UFMA - Centro de Ciências Agrárias e Ambientais - Chapadinha, Maranhão
} 
Existem equações para predizer o conteúdo de aminoácidos para diversos alimentos, como o sorgo (Mossé et al., 1988), cevada, triticale (Brandt et al., 2000), milheto (Rodrigues et al., 2001), milho e seus derivados (Cromwell et al., 1999; Rodrigues et al., 2001), trigo (Cervantes et al., 2002) e soja e seus derivados (Rodrigues et al., 2002). Na maioria das equações, a variável independente utilizada para estimar a concentração de aminoácidos é a proteína bruta, que pode ser estimada com rapidez e baixo custo.

O milho (Zea mays L.) é amplamente utilizado para alimentação de suínos e aves. Apesar de ser classificado como alimento energético (Cantarelli et al., 2007), contribui para o suprimento de aminoácidos em razão dos elevados níveis de participação das dietas de monogástricos. Rodrigues et al. (2001) propuseram equações de regressão $(\mathrm{LIS}=0,2649+0,0120 \mathrm{~PB} ; \mathrm{MET}=-0,0131+0,0203 \mathrm{~PB}$; $\mathrm{TRE}=0,0558+0,0341 \mathrm{~PB}$ ) para estimar o conteúdo de alguns aminoácidos essenciais, utilizando o teor de proteína do milho. Apesar das equações apresentarem alto coeficiente de determinação, foram calculadas utilizando-se apenas três amostras de milho com teores de proteína de 9,82, 8,07 e 7,67\%. De acordo com dados publicados recentemente, essa amostragem não reflete a ampla variação na quantidade de proteína bruta desse cereal. Analisando o conteúdo de proteína de vários híbridos de milho cultivados nos estados do Paraná e de Mato Grosso do Sul, constatou-se que os teores de proteína dos milhos variam dentro e entre regiões. $\mathrm{O}$ valor médio de proteína dos milhos estudados foi ao redor de 10,7\%, com valores mínimos e máximos de 8,31 e 13,32\%, respectivamente (Lima et al., 2002, 2003a,b,c, 2004).

Rodrigues et al. (2001) obtiveram equações com coeficiente de determinação acima de $85 \%$, mostrando que, quanto maior o conteúdo de proteína bruta, maior será a concentração dos aminoácidos. Entretanto, sabe-se que a adubação nitrogenada aumenta o teor de proteína do grão, mas também altera a proporção entre aminoácidos essenciais e compostos nitrogenados não protéicos (Vasconcellos, 1989). Isso significa que altos teores de proteína podem não estar associados a altos teores de aminoácidos, mas sim associados ao acúmulo de nitrogênio na forma de amônio e nitrato na planta e no grão (Schmidt et al., 2004). Se isso for verdadeiro, o nitrogênio não protéico existente no grão de milho poderia ser quantificado e os valores utilizados em equações de predição com o objetivo de aumentar a precisão da estimativa dos aminoácidos essenciais.

Sendo assim, o experimento foi conduzido para determinar a relação entre aminoácidos e frações nitrogenadas do grão de milho e verificar a possibilidade de utilizar tais relações para estimar o conteúdo de aminoácidos.

\section{MATERIAL E MÉTODOS}

Foram selecionadas, aleatoriamente, 45 amostras de diferentes híbridos comerciais de milho cultivados em diversas localidades da região oeste do Paraná, nas safras de 2005 e 2005/2006. Posteriormente, as 45 amostras foram agrupadas em três categorias de acordo com o teor de proteína bruta (PB): baixa (milhos com teor de PB abaixo do desvio padrão da média geral); média (milhos com teor de PB variando entre um desvio padrão abaixo e um desvio padrão acima da média geral); e alta (milhos com teor PB, acima de um desvio padrão da média geral). Posteriormente, foi selecionada uma sub amostra aleatória de $25 \%$ dentro de cada uma das categorias citadas anteriormente. Esse procedimento resultou em uma sub-amostra de 15 milhos que foram submetidos à análise de aminoácidos e teor de nitrogênio-não protéico. Os valores médios e coeficiente de variação da proteína bruta na sub amostra foram: 9,0 e 2,0; 9,72 e 3,5; e 11,05\% e 5,3\% , para as categorias baixa, média e alta, respectivamente.

Para determinação das análises químicas, as amostras foram moídas (Leite et al., 2008) e o conteúdo de matéria seca determinado em estufa a $105^{\circ} \mathrm{C}$ por 24 horas (Association of Official Analytical Chemist-AOAC, 1995). $\mathrm{O}$ teor de nitrogênio foi determinado pelo método micro Kjeldahl. O teor de nitrogênio não-protéico foi determinado utilizando, metodologia descrita pela AOAC (1975). O conteúdo de aminoácidos foi determinado por cromatografia líquida de fase reversa (Prates, 2002).

A estrutura de relação entre as variáveis independentes (proteína bruta e nitrogênio não-protéico) foi estudada por correlação de Pearson (Draper \& Smith, 1981). Em seguida, os modelos de regressão linear foram ajustados pelo método dos quadrados mínimos.

\section{RESULTADOS E DISCUSSÃO}

Na tabela 1, encontra-se o conteúdo médio de matéria seca e proteína bruta da amostra total $(\mathrm{N}=45)$ e sub amostra $(\mathrm{N}=15)$ dos milhos utilizados no estudo. Como se percebe, os valores médios e a variação calculadas com base na amostra e sub amostra são próximos, indicando que a sub amostra refletiu as características da amostra total para as variáveis matéria seca e proteína bruta.

$\mathrm{O}$ conteúdo médio de $\mathrm{PB}$ dos milhos analisados foi de $9,79 \%$, com desvio padrão de 0,69 e valores de mínimo e de máximo de 8,48 e 12,02\%, respectivamente (Tabela 2). 
Tabela 1 - Valores médios e desvio padrão da matéria seca (MS) e proteína bruta (PB) calculadas com base na amostra e sub amostra.

\begin{tabular}{lccc}
\hline Variável & $\mathrm{N}$ & Média & Desvio Padrão \\
\hline MS (\%) & 45 & 88,71 & 0,75 \\
PB (\%) & 45 & 9,79 & 0,69 \\
\hline MS (\%) & 15 & 88,38 & 0,84 \\
PB (\%) & 15 & 9,80 & 0,65 \\
\hline
\end{tabular}

Verifica-se que, aproximadamente, $78 \%$ das amostras apresentaram teor de proteína dentro da faixa situada entre um desvio padrão abaixo e acima da média geral. Em levantamentos realizados em cidades da região oeste do Paraná, constatou-se que o teor de PB apresentou média, valor mínimo e máximo de 10,32; 8,39 e 13,32\%, respectivamente (Schimidt et al., 2004). Observa-se que a média e a dispersão dos valores de proteína, obtidas no presente experimento, foram levemente inferiores em relação àquelas descritas por esses autores. Diversos fatores como genética, solo, nível de adubação, época de plantio e outros podem influenciar o teor de PB do grão de milho (Fuller, 1989; Summers, 2001).

Os teores médios de PB, NT, NNP, proteína bruta corrigida $(\mathrm{PBc})$, lisina (LIS), metionina (MET), metionina+cistina (MET+CIS), treonina (TRE), valina (VAL), isoleucina (ISO), leucina (FEN), fenilalanina (FEN), histidina (HIS) e arginina (ARG) são mostrados na tabela 2.

Os teores médios de NNP foram relativamente baixos, atingindo pouco mais de $5 \%$ do NT, embora tenham sido detectados valores mínimo e máximo de 4,08 e 6,56\%, respectivamente. Azevedo et al. (2003) analisaram diferentes híbridos de milho e verificaram que o NNP representou, em média, 2,3\% do nitrogênio total. Em grãos de sorgo foram obtidos valores de NNP relativamente constantes e próximos de 5\% (Mossé et al., 1988). Diferenças genéticas e ambientais entre as amostras utilizados nos estudos e a metodologia analítica empregada podem ter determinados essas variações. De qualquer maneira, é importante observar que a quantidade de NNP do grão de milho é relativamente baixa e isso determinou pequenas diferenças entre a PB e PBc. Com relação aos aminoácidos, percebe-se que os valores médios analisados foram próximos aos citados por Rostagno et al. (2005).

Na tabela 3, encontram-se os parâmetros de regressão ajustados para cada um dos aminoácidos (\% da MS), utilizando como variável independente a proteína bruta.

Os coeficientes angulares das retas dos primeiros aminoácidos limitantes para aves e suínos (LIS, MET, e TRE) foram positivos e significativos $(\mathrm{P}<0,05)$, indicando que a concentração de aminoácidos essenciais, expressos

Tabela 2 - Tamanho da amostra $(\mathrm{N})$, valores médios, mínimos, máximos e desvios padrões das variáveis analisadas (\% da matéria seca).

\begin{tabular}{lccccc}
\hline Variável & N & Média & Mínimo & Máximo & Desvio padrão \\
\hline NT & 15 & 1,57 & 1,43 & 1,83 & 0,11 \\
PB & 15 & 9,80 & 8,95 & 11,46 & 0,65 \\
NNP (\% do NT) & 15 & 5,23 & 4,08 & 6,56 & 0,74 \\
PBc & 15 & 9,31 & 8,40 & 11,05 & 0,65 \\
LIS & 15 & 0,24 & 0,23 & 0,28 & 0,01 \\
MET & 15 & 0,19 & 0,17 & 0,20 & 0,01 \\
MET+CIS & 15 & 0,38 & 0,36 & 0,41 & 0,01 \\
TRE & 15 & 0,31 & 0,28 & 0,35 & 0,02 \\
VAL & 15 & 0,42 & 0,38 & 0,48 & 0,03 \\
ISO & 15 & 0,30 & 0,26 & 0,34 & 0,02 \\
LEU & 15 & 1,07 & 0,95 & 1,24 & 0,08 \\
FEN & 15 & 0,42 & 0,38 & 0,50 & 0,03 \\
HIS & 15 & 0,26 & 0,25 & 0,29 & 0,01 \\
ARG & 15 & 0,43 & 0,39 & 0,47 & 0,02 \\
\hline
\end{tabular}

$\mathrm{NT}=$ nitrogênio total; $\mathrm{PB}=$ proteína bruta; $\mathrm{NNP}=$ nitrogênio não-protéico; $\mathrm{PBc}=$ proteína bruta corrigida; LIS=lisina; MET=metionina; MET+CIS=metionina mais cistina; TRE=treonina; $\mathrm{VAL}=$ valina; $\mathrm{ISO}=$ isoleucina; $\mathrm{LEU}=$ leucina; FEN=fenilalanina; HIS=histidina; $A R G=$ arginina 
em proporção da matéria seca do grão, é influenciada pelo conteúdo de proteína bruta. Contudo, os coeficientes de determinação das equações foram abaixo de 0,51 , evidenciando que a proteína bruta explica apenas parte da variação no conteúdo de aminoácidos do grão de milho. Coeficientes de determinação baixos também foram observados em outros estudos com grãos de milho: 0,38 e 0,49, e de 0,49 e 0,25 para lisina e metionina, respectivamente (Ficker, 1995; Cromwell et al., 1999).

Tabela 3 - Parâmetros das regressões lineares e principais estatísticas das equações obtidas para estimar o conteúdo de aminoácidos (\% da matéria seca), tendo a proteína bruta (PB) como variável independente.

\begin{tabular}{lcccc}
\hline Aminoácido & $\mathrm{B}_{0}$ & $\beta_{1}$ & $\mathrm{P}^{2}$ & $\mathrm{R}^{2}$ \\
\hline LIS & 0,1080 & 0,0140 & 0,0136 & 0,39 \\
MET & 0,1015 & 0,0084 & 0,0079 & 0,43 \\
MET+CIS & 0,2446 & 0,0141 & 0,0082 & 0,43 \\
TRE & 0,1268 & 0,0184 & 0,0029 & 0,51 \\
VAL & 0,1586 & 0,0264 & 0,0227 & 0,34 \\
ISO & 0,0878 & 0,0210 & 0,0104 & 0,41 \\
LEU & 0,3430 & 0,0744 & 0,0238 & 0,33 \\
FEN & 0,0688 & 0,0359 & 0,0054 & 0,46 \\
HIS & 0,1237 & 0,0312 & 0,0006 & 0,61 \\
ARG & 0,2313 & 0,0197 & 0,0232 & 0,34 \\
\hline
\end{tabular}

${ }^{1} \mathrm{LIS}=$ lisina; $\mathrm{MET}=$ metionina; $\mathrm{MET}+\mathrm{CIS}=$ metionina mais cistina; TRE=treonina; VAL=valina; $I S O=$ isoleucina; LEU=leucina; FEN=fenilalanina; HIS=histidina; $A R G=$ arginina. ${ }^{2} \mathrm{H}_{0}: \beta_{1}=0$

Estes resultados podem ter ocorrido em razão de mudanças nas proporções das proteínas acumuladas nos grãos, genericamente denominadas de zeínas e não-zeinas (albuminas, globulinas e glutelinas). Sabe-se que o aumento do conteúdo de proteína observado em decorrência da adubação nitrogenada resulta em diminuição da participação das zeínas, localizadas predominantemente no endosperma e que, ao contrário das não-zeínas, são deficientes em alguns aminoácidos, como lisina e triptofano (Yau et al., 1999). Sendo assim, ao mesmo tempo em que é esperado aumento linear do conteúdo de aminoácidos com o acúmulo das diferentes proteínas, também é razoável admitir que qualquer alteração no tipo de proteína depositada no grão contribua para a dificuldade na obtenção de relações mais estreitas entre aminoácidos e proteína bruta. Talvez a quantificação das diferentes proteínas do grão (zeínas e não-zeínas) e a utilização dessas informações nas equações permita predizer o conteúdo de aminoácidos do milho com maior precisão.

Por outro lado, parte do nitrogênio acumulado no grão está na forma de compostos nitrogenados nãoprotéicos (NNP). Há indicações de que o incremento do conteúdo de proteína, em razão da adubação nitrogenada, resulta em aumento da relação entre NNP e nitrogênio total do grão de milho. Assim, a quantificação do NNP e, seu uso para correção do cálculo da proteína bruta, poderia diminuir o viés das equações. Contudo, como se verifica na tabela 4 , esse procedimento não foi eficaz, pois não melhorou o ajuste das equações aos dados. Possivelmente, isso ocorreu em razão da baixa concentração e da pequena variação no conteúdo de NNP encontrado nas amostras analisadas.

Tabela 4 - Parâmetros das regressões lineares e principais estatísticas das equações obtidas para estimar o conteúdo de aminoácidos ( $\%$ da matéria seca), tendo a proteína bruta corrigida $(\mathrm{PBc})$ como variável independente.

\begin{tabular}{lcccc}
\hline Aminoácido $^{1}$ & $\mathrm{~B}_{0}$ & $\beta_{1}$ & $\mathrm{P}<^{2}$ & $\mathrm{R}^{2}$ \\
\hline LIS & 0,1123 & 0,0143 & 0,0110 & 0,40 \\
MET & 0,1062 & 0,0083 & 0,0083 & 0,43 \\
MET+CIS & 0,2553 & 0,0137 & 0,0106 & 0,41 \\
TRE & 0,1324 & 0,0187 & 0,0020 & 0,53 \\
VAL & 0,1591 & 0,0277 & 0,0149 & 0,38 \\
ISO & 0,0880 & 0,0221 & 0,0059 & 0,45 \\
LEU & 0,3397 & 0,0785 & 0,0149 & 0,38 \\
FEN & 0,0765 & 0,0369 & 0,0035 & 0,49 \\
HIS & 0,1308 & 0,0142 & 0,0006 & 0,61 \\
ARG & 0,2663 & 0,0202 & 0,0186 & 0,36 \\
\hline
\end{tabular}

${ }^{1}$ LIS=lisina; MET=metionina; MET+CIS=metionina mais cistina; TRE=treonina; VAL=valina; $I S O=$ isoleucina; LEU=leucina; FEN=fenilalanina; HIS=histidina; $A R G=$ arginina. ${ }^{2} \mathrm{H}_{0}: B_{1}=0$

Os conteúdos de proteína bruta (PB), proteína bruta corrigida $(\mathrm{PBc})$ e dos aminoácidos lisina (LIS), metionina (MET), metionina e cistina (MET+CIS), treonina (TRE), valina (VAL), isoleucina (ISO), leucina (FEN), fenilalanina (FEN), histidina (HIS) e arginina (ARG), expressos em porcentagem da proteína bruta, são apresentados na tabela 5 .

Os primeiros aminoácidos limitantes (LIS, MET e TRE) representam uma pequena proporção da $\mathrm{PB}(2,49$, 1,89 e $3,14 \%$, respectivamente). Dessa forma, fica evidente que a proteína do milho apresenta baixo valor biológico para suínos e aves. Contudo, essa situação é amenizada em virtude da alta proporção do milho e da inclusão de alimentos protéicos, como é o caso do farelo de soja, nas dietas desses animais (Zangeronimo et al., 2009). 
Tabela 5 - Tamanho da amostra $(\mathrm{N})$, valores médios, mínimos, máximos e desvio padrão das variáveis analisadas (aminoácidos expressos em proporção da proteína).

\begin{tabular}{lccccc}
\hline Variável & N & Média & Mínimo & Máximo & Desvio padrão \\
\hline PB $(\%$ da MS) & 15 & 9,80 & 8,95 & 11,46 & 0,65 \\
PBc (\% da MS) & 15 & 9,31 & 8,40 & 11,05 & 0,65 \\
LIS & 15 & 2,49 & 2,33 & 2,82 & 0,14 \\
MET & 15 & 1,89 & 1,76 & 2,08 & 0,09 \\
MET+CIS & 15 & 3,93 & 3,62 & 4,28 & 0,19 \\
TRE & 15 & 3,14 & 2,90 & 3,43 & 0,15 \\
VAL & 15 & 4,27 & 3,87 & 4,92 & 0,27 \\
ISO & 15 & 3,02 & 2,77 & 3,43 & 0,19 \\
LEU & 15 & 10,95 & 9,71 & 12,61 & 0,75 \\
FEN & 15 & 4,30 & 3,91 & 4,90 & 0,25 \\
HIS & 15 & 2,69 & 2,54 & 2,94 & 0,11 \\
ARG & 15 & 4,34 & 4,02 & 4,66 & 0,23 \\
\hline
\end{tabular}

$\mathrm{MS}=$ materia seca; $\mathrm{PBc}=$ proteína bruta corrigida; $\mathrm{LIS}=$ lisina; $\mathrm{MET}=$ metionina; $\mathrm{MET}+\mathrm{CIS}=$ metionina mais cistina; TRE=treonina; $\mathrm{VAL}=$ valina; $\mathrm{ISO}=$ =isoleucina; $\mathrm{LEU}=$ leucina; $\mathrm{FEN}=$ fenilalanina; $\mathrm{HIS}=$ histidina; $\mathrm{ARG=arginina.}$

Na tabela 6, estão listados os parâmetros de regressão dos aminoácidos do grão de milho, expressos como porcentagem da proteína e utilizando-se como variável independente a proteína bruta.

Tabela 6 - Parâmetros das regressões lineares e principais estatísticas das equações obtidas para estimar o conteúdo de aminoácidos (expressos em proporção da proteína), tendo a proteína bruta (PB) como variável independente.

\begin{tabular}{lcccc}
\hline Aminoácido $^{1}$ & $\mathrm{~B}_{0}$ & $\beta_{1}$ & $\mathrm{P}<$ & $\mathrm{R}^{2}$ \\
\hline LIS & 3,5644 & $-0,1094$ & 0,0587 & 0,23 \\
MET & 2,8688 & $-0,0995$ & 0,0039 & 0,49 \\
MET+CIS & 6,2054 & $-0,2325$ & 0,0004 & 0,63 \\
TRE & 4,4766 & $-0,1357$ & 0,0246 & 0,33 \\
VAL & 5,8678 & $-0,1632$ & 0,1522 & 0,15 \\
ISO & 4,1126 & $-0,1112$ & 0,1663 & 0,14 \\
LEU & 14,3726 & $-0,3478$ & 0,2793 & 0,09 \\
FEN & 4,9063 & $-0,6170$ & 0,5768 & 0,02 \\
HIS & 3,8347 & $-0,1158$ & 0,0078 & 0,43 \\
ARG & 6,5888 & $-0,2284$ & 0,0086 & 0,42 \\
\hline
\end{tabular}

${ }^{1}$ LIS=lisina; MET=metionina; MET+CIS=metionina mais cistina; TRE=treonina; VAL=valina; $I S O=$ isoleucina LEU=leucina; FEN=fenilalanina; $H I S=$ histidina; $A R G=$ arginina ${ }^{2} \mathrm{H}_{0}: \beta_{1}=0$

É interessante observar que o coeficiente de regressão foi negativo nas equações de todos os aminoácidos. Esses resultados estão em conformidade com os obtidos por Cervantes et al. (2002) estudando o trigo. Da mesma forma, Mossé et al. (1988) observaram que a concentração de LIS aumentou com a concentração de proteína no grão, mas diminuiu quando os dados foram expressos em proporção da proteína bruta. Baudet et al. (1986) constataram que proteínas de grãos de milho contendo nitrogênio ao redor de 1 porcento da materia seca (baixa PB) apresentaram concentração 50 e $60 \%$ maior de triptofano e lisina, respectivamente, comparados a milhos com conteúdo de nitrogênio próximo a 3 (alta $\mathrm{PB}$ ). a relação entre aminoácidos (\% da PB) e proteína bruta é melhor descrita por uma hipérbole, sugerindo relação não-linear entre essas aminoácidos e proteína bruta.

Os dados obtidos no presente experimento demonstram que, com o aumento da PB no grão de milho, diminui a participação dos aminoácidos estudados na constituição dessa proteína. As diferenças entre os perfis de aminoácidos das proteínas armazenadas no grão de milho (zeínas e não- zeínas), possivelmente contribuíram para esses resultados.

No presente experimento, foram avaliados, conjuntamente, diversos híbridos de milho cultivados em diferentes condições ambientais. Como a composição da proteína é influenciada pelo genótipo, ambiente e pela interação desses fatores (Zhu \& Khan, 2001), não se pode excluir a hipótese de que, considerando híbridos específicos ou condições ambientais padronizadas, seja possível detectar relação linear entre proteína bruta do grão e aminoácidos. 


\section{CONCLUSÕES}

Não é possível estimar o conteúdo de aminoácidos essenciais do grão de milho, utilizando as concentrações de proteína bruta ou proteína bruta corrigida.

\section{REFERÊNCIAS BIBLIOGRÁFICAS}

\section{ASSOCIATION OF OFFICIAL ANALITYCAL} CHEMIST. Official methods of analysis of AOAC. 12.ed. Washington, 1975. 1094p.

\section{ASSOCIATION OF OFFICIAL ANALITYCAL CHEMIST. Official methods of analysis of AOAC. 15.ed. Arlington, 1995. 2v.}

AZEVEDO, A.R.; DAMERVAL, C.; LANDRY, J.; LEA, P.J.; BELLATO, C.M.; MEINHARDT, L.; GUILLOUX, M.L.; DELHAYE, S.; TORO, A.A.; GAZIOLA, S.A.; BERDEJO, B.D.A. Regulation of maize lysine metabolism and endosperm protein synthesis by opaque and floury mutations. European Journal of Biochemistry, Cambridge, v.270, n.24, p.4898-4908, 2003.

BAUDET, J.; HUET, J.C.; MOSSÉ, J. Variability and relationships among amino acids and nitrogen in maize grain. Journal of Agricultural and Food Chemistry, Washington, v.34, n.2, p.365-370, 1986.

BRANDT, D.A.; BRAND, T.T.; CRUYWAGEN, C.W. The use of crude protein content to predict concentrations of lysine and methionine in grains harvested from selected cultivars of wheat, barley and triticale grown in the Western Cape region of South Africa. South African Journal of Animal Science, Pretoria, v.30, n.1, p.22-25, 2000 .

CANTARELLI, V. de S.; FIALHO, E. T.; SOUZA, R. V. de; FREITAS, R. T. F. de; LIMA, J. A. F. de. Composição química, vitreosidade e digestibilidade de diferentes híbridos de milho para suínos. Ciência e

Agrotecnologia, Lavras, v. 31, n. 3, p. 860-864, maio/jun., 2007.

CERVANTES, M.; COPADO, F.; CERVANTES, M.; SOTO, R.; TORRENTERA, N.; FIGUEROA, J.L.

Prediction del contenido de aminoácidos em el trigo com base em su valor de proteína. Interciencia, Caracas, v.27, n.12, p.695-701, 2002.

CROMWELL, G.L.; CALVERT, C.C.; CLINE, T.R.; CRENSHAW, J.D.; EASTER, R.A.; EWAN, R.C.
Variability among sources and laboratories in nutrient analyses of corn and soybean meal. Journal of Animal Science, Champaign, v.77, n.10, p.3262-3273, 1999.

DRAPER, N.R.; SMITH, H. Applied regression analysis. 2.ed. New York: J.Wiley, 1981. 709p.

FICKER, J. La variación de amino ácidos em los principales ingredientes com energia. Alimentos Balanceados para Animales, Mt. Morris: Watt, 2000. 23p.

FULLER, C.A.; BROWN, D.S.; BREWER, A.C.; CARVER, M.; ROBINSON, R. Varietal differences in the nutritive value of cereal grains for pigs. Journal of Agricultural Science, Cambridge, v.113, n.1, p.149-163, 1989.

LEITE, J. L. B.; RODRIGUES, P. B.; FIALHO, E. T.; FREITAS, R. T. F. de; NAGATA, A. K.; CANTARELLI, V. de S. Efeito da peletização e adição de enzimas e vitaminas sobre o desempenho e aproveitamento da energia e nutrientes em frangos de corte de 1 a 21 dias de idade. Ciência e Agrotecnologia, Lavras, v. 32, n. 4, p.1292-1298, jul./ago., 2008.

LIMA, G.J.M.M.; CANZIANI FILHO, N.J.; PITOL, C.; SANGOI, S.; KLEIN, C.H.; SCHMIDT, A. Teores de óleo e proteína bruta de híbridos comerciais de milho testados no Sindicato Rural de São Gabriel do Oeste, MS, na safrinha de 2003. Concórdia: Embrapa/CNPSA, 2004. 4p. (Comunicado técnico, 359).

LIMA, G.J.M.M.; GUIDELI, C.A.; KLEIN, C.H.; SANGOI, $\mathrm{S}$. Avaliação do teor de óleo e proteína bruta de genótipos de milho produzidos na Coopervale - Palotina, PR. Concórdia: Embrapa/CNPSA, 2003a. 4p. (Comunicado técnico, 346).

LIMA, G.J.M.M.; PITOL, C.; CANZIANI FILHO, N.J.; KLEIN, C.H.; SCHMIDT, A.; SANGOI, S. Óleo e proteína bruta de híbridos comerciais de milho testados em Maracajú, MS, na safrinha de 2003. Concórdia: Embrapa/CNPSA, 2003b. 4p. (Comunicado técnico, 345).

LIMA, G.J.M.M.; SANGOI, S.; KLEIN, C.H.; PITOL, C.; CANZIANI FILHO, N.J. Composição química de híbridos comerciais de milho testados no Sindicato Rural de São Gabriel do Oeste, MS, na safra de verão de 2002/2003. Concórdia: Embrapa/CNPSA, 2003c. 3p. (Comunicado técnico, 333). 
LIMA, G.J.M.M.; SCHMIDT, A.; SANGOI, S.; KLEIN, C.H.; PEREIRA, L.R.; BELLAVER, C. Composição química de híbridos comerciais de milho testados na Cooperativa Agrícola Mista Vale do Piquiri

(Coopervale) - Palotina, PR., na safrinha 2001.

Concórdia: Embrapa/CNPSA, 2002. 8p. (Comunicado técnico, 311).

MOSSÉ, J.; HUET, J.C.; BAUDET, J. The amino acid composition of whole sorghum grain in relation to its nitrogen content. Cereal Chemistry, Saint Paul, v.65, n.4, p.271-277, 1988.

PRATES, H.T. Metodologia para análise de aminoácidos protéicos em grãos de milho. Sete Lagoas: Embrapa/ CNPMS, 2002. 21p. (Documentos, 22).

RODRIGUES, P.B.; ROSTAGNO, H.S.; ALBINO, L.F.T.; GOMES, P.C.G.; BORBOZA, W.A.; NUNES, R.V.

Aminoácidos digestíveis verdadeiros do milheto, do milho e subprodutos do milho determinados com galos adultos cecectomizados. Revista Brasileira de Zootecnia, Viçosa, v.30, n.6, p.2046-2058, 2001. Suplemento.

RODRIGUES, P.B.; ROSTAGNO, H.S.; ALBINO, L.F.T.; GOMES, P.C.G.; TOLEDO, R.T.; NUNES, R.V.

Aminoácidos digestíveis verdadeiros da soja e subproduto. Revista Brasileira de Zootecnia, Viçosa, v.31, n.2, p.970-987, 2002. Suplemento.

ROSTAGNO, H.S.; ALBINO, L.T.F.; DONZELE, J.L.; GOMES, P.C.; FERREIRA, A.S.; OLIVEIRA, R.F.; LOPES, D.C. Tabelas brasileiras para aves e suínos: composição de alimentos e exigências nutricionais. 2.ed. Viçosa, MG: UFV, 2005. 186p.
SCHMIDT, A.; LIMA, G.J.M.M.; KLEIN, C.H. Composição química de híbridos de milho produzidos na safrinha em Marechal Cândido Rondon, Paraná. Concórdia: Embrapa/CNPSA, 2004. 4p. (Comunicado técnico, 357).

SUMMERS, J.D. Maize: Factors affecting its digestibility and variability in its feeding value. In: BEDFORD, M.R.; PARTRIDGE, C.G. Enzymes in animal nutrition. London: CAB International, 2001. p.109-124.

VASCONCELLOS, C.A. Importância da adubação na qualidade de milho e do sorgo. In: SIMPÓSIO SOBRE ADUBAÇÃO E QUALIDADE DOS PRODUTOS AGRÍCOLAS, 1., 1989, Ilha Solteira. Anais... Ilha Solteira: FEIS/UNESP/ANDA/POTAFOS, 1989. p.319330.

YAU, J.C.; BOCKHOLT, A.J.; SMITH, J.D.; ROONEY, L.W.; WANISKA, R.D. Maize endosperm proteins that contribute to endosperm lysine content. Cereal Chemistry, Saint Paul, v.76, n.5, p.668-672, 1999.

ZANGERONIMO, M. G.; FIALHO, E. T.; MURGAS, L. D. S.; SOUSA, R. V. de; LIMA, J. A. de F.; AMARAL, N. de O. Corporal composition of swine feed from 10 to $20 \mathrm{~kg}$ with diets containing different levels of lysine and crude protein. Ciência e Agrotecnologia, Lavras, v. 33, n. 6, p.1627-1636, nov./dez., 2009.

ZHU, J.; KHAN, K. Effects of genotype and environment on glutenin polymers and breadmaking quality. Cereal Chemistry, Saint Paul, v.78, n.2, p.125130, 2001. 